\title{
Analítica da literatura: Análise sobre a natureza lógica do "indizível"
}

\section{The analytics of literature: Analysis of the logical nature of the "unsayable"}

\section{Rodrigo César Lima}

Graduação em andamento em Filosofia. Pontifícia Universidade Católica de São Paulo - PUC-SP. Faculdade de Filosofia, Comunicação, Letras e Artes. São Paulo, SP - Brasil.

Resumo: Não foram poucas as tentativas de se levar a filosofia ao fim e ao cabo por meio da literatura. Talvez o maior exemplo desse empreendimento tenha sido a obra de Sartre, que "diluiu" seu rol de conceitos filosóficos em inúmeros trabalhos literários - sempre sem o efeito desejado, segundo ele mesmo. O objetivo do presente artigo é demonstrar que a literatura funciona pelo fato de que descreve uma forma lógica possível, aquilo que poderia ser, mas não o que se tem de fato. Assim, a literatura tenciona preencher ontologicamente essa forma lógica possível. Todavia, ao fazê-lo filosoficamente, falha em seu objetivo primordial de descrever a filosofia do nosso mundo, pois elucida algo próprio ao seu universo e não deste - é, portanto, uma "filosofia ficcional" que se aplica ao mundo descrito, mas que não funciona no mundo real.

Palavras-chave: literatura; filosofia; ontologia; forma lógica.

\begin{abstract}
Innumerable were the attempts to carry out philosophy through literature. Perhaps the greatest example of this fact was the work of Sartre which "diluted" his philosophical concepts into several literary works - always unsuccessfully, according to himself. This article intends to demonstrate that literature works because it describes a possible logical form, that which could be, but it is not. Therefore, literature tries to ontologically fill up this possible logical form. However, in doing so philosophically, it fails in its primordial goal while describing our world's philosophy, because it elucidates an aspect of its own universe, but not ours - thus, it is an applicable "fictional philosophy" to the described universe, but that does not work in the real world.
\end{abstract}

Keywords: literature; philosophy; ontology; logical form. 


\section{O que é a literatura?}

Explicar o que seja a literatura pode parecer uma tarefa fácil de início, mas examinando-se todas as suas possíveis interpretações, gêneros, estilos, matizes e teores, subitamente nos vemos diante de um assunto hercúleo, extremamente complexo - cuja definição completa e totalizante beira a sandice. Se ressaltarmos um aspecto, esqueceremos de outro; se preferirmos determinado especialista, incorremos na possibilidade de irritar um segundo, um terceiro e centenas de outros teóricos. De modo que, até hoje, permanece a literatura um assunto em aberto, um assunto que continua a ser feito nesse instante e que também o será no futuro, tal como todas as temáticas complexas que pautam a criação humana. Afinal, como definir a arte, a filosofia, a matemática? É possível encontrarmos uma definição totalizante para cada uma dessas searas? Assim, para bem evitar a controvérsia, faremos uma escolha bem marcante de início: literatura será a descrição ou criação literária de algo ou alguma coisa dentro da esfera do possível; melhor ainda, literatura é o gênero escrito ao qual compete descrever mundos possíveis. Nessa definição abrangente cabem as mais diversas categorias, indo desde a epopeia até o romance, passando pela biografia até a autoajuda. Esses mundos possíveis dividem-se essencialmente em duas espécies: 0 nosso mundo (que geralmente é apresentado como o pano de fundo das biografias, da filosofia e da história) ou mundos imaginados/especulados (que serão o pano de fundo da ficção, romance, religião - algo ao qual alude a ampla maioria das pessoas quando se referem ao termo "literatura").

No entanto, surge aqui um empecilho logo de início. O nosso mundo também serve de base para inúmeras criações. Os romances de Dostoievski são exemplares nesse sentido ${ }^{1}$ - passam-se na Rússia em cidades como Moscou ou Petersburgo, por vezes os protagonistas da história (personagens ficcionais) entabulam relações com personagens verídicos (portanto, personagens históricos) e emulam ações similares às que podemos realizar (assassinatos, guerras, diálogos etc.). Ora, como então é possível distinguir o nosso mundo do mundo imaginado, sobretudo quando personagens reais tornam-se personagens romanescos? ${ }^{2}$ ? Foi Granger (1978) um dos primeiros pensadores a analisar essa potencialidade. Segundo ele, a linguagem permite a criação de mundos possíveis, muito próximos ao que nós mesmos podemos experimentar, mas que, no entanto, permanecem completamente inacessíveis - problema é que podem nos enganar ao ponto de que pensamos serem estes mundos possíveis de mesma valia ao nosso mundo. Isso é sedutor na mesma medida que perigoso. Por outro lado, tais mundos deixam em aberto uma perspectiva fascinante a filósofos e pensadores dos mais variados estilos, pois que temos a nítida impressão de que a literatura ficcional estaria de "portas abertas" à filosofia. Nesse sentido, no que tange à mescla entre literatura e filosofia, nenhum pensador foi tão a fundo quanto Sartre - ainda que sem o efetivo sucesso desejado, tal como ele mesmo viria a admitir já no final de sua vida.

De início, Sartre vira na literatura uma possibilidade de se fazer a filosofia - melhor ainda, em colocar com exemplos, situacionalmente, as condições filosóficas que advogava. Seria uma forma de criar uma ponte entre situações concretas e a universalidade da condição de contingência humana. Caberia ao homem decidir tomar as rédeas da própria escolha ao saber que nada é necessário nem predeterminado. A ação é temática tipicamente humana e o que nós faremos compete única e exclusivamente a nós - não somos regidos por qualquer preceito. Assim:

\footnotetext{
${ }^{1}$ E inúmeros são os exemplos nesse caso. Crime e Castigo, O Idiota, O Jogador, são obras todas que podem ocupar e exemplificar as categorias que aqui abordamos.

${ }^{2}$ Pensamos aqui nas obras de Tolstói, por exemplo, quando personagens históricos (o general Kutuzov, o czar Alexandre I, Napoleão etc.) transformam-se em personagens romanescos de Guerra e Paz.
} 
Podemos concluir que o escritor decidiu desvendar o mundo e especialmente o homem para os outros homens, a fim de que estes assumam em face do objeto, assim posto a nu, a sua inteira responsabilidade. (SARTRE, 2004, p. 21)

Ou seja, em tese caberia ao escritor propor os dilemas humanos em crises muito concretas, e as tensões refletir-se-iam no sentido particular daquilo que seria a condição humana - como se a crise no papel fosse consonante à crise do próprio leitor. A literatura, portanto, poderia assumir um papel de facilitadora da filosofia, ao mostrar, ao menos no escopo ideal sartreano, a concretude dos conceitos filosóficos em situações possíveis. Tal como nos sugerem os comentadores, Sartre tinha em mente fazer uso de novas técnicas da filosofia tentando aplicá-las também à sua escrita literária:

\begin{abstract}
Nessa reinvenção da escrita, a Fenomenologia vem trazer uma caução maior. Husserl, com efeito, esclarece e legitima duas operações praticadas por Sartre: a suspensão da adesão da escrita à existência e o emprego do imaginário a serviço da verdade. Sob certas condições, as descrições, além do valor estético, constituem instrumentos de operação verídica do real. A ficção aí desempenha um papel determinante, uma vez que a invenção de "variações eidéticas" imaginárias é a única maneira de colocar em evidência a contingência que advém e a constituição dos fenômenos que surgem. (SAINT-SERNIN, 1990, apud LEOPOLDO E SILVA, 2004, p. 46)
\end{abstract}

A questão é saber como e por que isso seria possível, e se de fato (empregando o termo dos comentadores acima) as descrições daí derivadas constituem operações ultimamente verídicas no que toca à constituição do real. Esmiuçar esta questão será nossa tarefa mais a seguir. Sartre, à sua vez, chegou perto da explicação ao propor o seguinte:

Quanto à forma, não há nada a dizer de antemão e nada dissemos: cada um inventa a sua e só depois é que se julga (...). Não há temas situados a priori. (SARTRE, 2004, p. 23)

Advogamos aqui, no entanto, que a forma condiciona por completo a natureza da literatura. Esta foi uma das razões pelas quais a tentativa literária sartreana de ir além da facticidade como exploração totalizadora no âmbito da vivência imediata e da elucidação analítica ${ }^{3}$ ao mostrá-la enquanto filosofia ruiu; ao reconhecê-lo, coube a ele desistir da empreitada. Não que a composição resultante dessa perspectiva seja inválida, muito pelo contrário - a reputação de obras como A Náusea e Huis Clos/Entre Quatro Paredes ${ }^{4}$ é fato que não nos deixa mentir nesse sentido. A concretude de nosso mundo, porém, que aparece com força na filosofia, não esteve vinculada nessas obras. Isto é, a força da realidade que se impinge contra nós resume-se a um cenário ficcional na literatura. Foi essa mesma reflexão que levou Gilles Deleuze, anos mais tarde, a propor que a literatura não consegue erigir conceitos - e daí em diante, juntamente a Guattari, propôs-se o conceito de "literatura menor" que até hoje permanece em voga, sobretudo na filosofia francesa, a fim de explicar as diferenças entre filosofia e literatura ${ }^{5}$. O que salta aos olhos é que a filosofia exige recursos de conceptualizações próprios acerca de nosso mundo - ela não permite saltos abruptos; nem mesmo a maior técnica literária pode acobertar os erros do filósofo se este não puder explicitar exatamente de onde retira as suas mais belas reflexões. Aqui a qualidade literária é mero recurso, técnica esta que pode ser, inclusive, dispensada. Na literatura, dá-se o contrário: pode-se fazer um belo livro sem nenhuma necessidade de esmiuçar o raciocínio filosófico por detrás de si - aliás, abundam os livros assim chamados de

\footnotetext{
${ }^{3}$ Cf. Franklin Leopoldo e Silva, 2004, pp. 46-47.

${ }^{4}$ Publicadas em 1938 e 1944, respectivamente.

${ }^{5}$ Para tanto, é mister consultar o ensaio Kafka, pour une littérature mineure, publicado por Deleuze e Guattari em 1975.
} 
"anti-filosóficos". Tal como Granger (1978) nos relembra, a confusão se dá nos usos da linguagem. É mister saber separar a linguagem de nosso mundo e dos mundos possíveis, é de suma importância ponderar acerca do fato de que certas invenções da linguagem não são reais porque possíveis, e que nem todas as possibilidades lógicas se concretizam.

\section{A forma lógica do dizível}

À primeira vista, quando pensamos ou escrevemos qualquer coisa, imaginamos que possamos fazê-lo ilogicamente - ora, esse ponto é um grande problema. Indo-se mais além podemos inclusive conjecturar que tal perspectiva seja uma grande mentira. Obviamente que quando pensamos ou escrevemos podemos enveredar por uma sequência sem nenhum sentido, por exemplo: "cachorro prédio e chove psicologia à computador"; podemos, inclusive, inventar uma linguagem própria. Mas então estaremos em um mapa mental individual que não fará nenhum sentido coletivamente - seremos incapazes de comunicar qualquer fato a alguém. A linguagem individual é coisa impossível. Deve haver, portanto, algo de comum ao código linguístico que partilhamos de acordo com a sociedade na qual nos inserimos. Os signos que representam serão sempre uma construção coletiva - o significado das coisas também é coletivo ${ }^{6}$. Uma linguagem solipsista nem sequer poderia ser chamada de linguagem ${ }^{7}$. Foi Wittgenstein quem sugeriu e dissecou essa gama de conceitos. Se hoje temos essa referência, isso se deve ao seu segundo trabalho (Investigações Filosóficas ${ }^{8}$ ).

Em todo caso, a literatura depende amplamente dessa concepção. É uma coleção escrita de signos a representar significados coletivos que, dispostos logicamente - isto é, não havendo contradição lógica entre os termos (exemplo: chove e não chove) -, nos permite dar sentido a algo ou a alguma coisa. Em suma, é assim que a literatura imprime significado aos mundos possíveis que elabora. Mas, ao fazê-lo, precisa enveredar por formas lógicas pré-definidas, e foi essa exigência que Sartre deixou escapar quando falou do a priori na literatura - isto veremos mais a seguir. A literatura trabalha com a linguagem, melhor ainda, subordina-se a esta em um nível total de dependência - em certa medida, podemos inclusive supor que seja um "parasita" dela. Sem a linguagem a literatura morreria, mas a primeira não desapareceria sem a segunda. No entanto, quando a linguagem se beneficia da literatura, pode ocorrer que tenhamos uma espécie de "mutualismo" e assim essas duas esferas se refinariam. A linguagem ganharia então riqueza de detalhes e maior poder de expressão, na medida em que a literatura poderia continuar a coexistir com aquela. Outra forma de se analisar essa situação é perceber que a linguagem é uma propedêutica em relação à literatura - é um ramo anterior e necessário à realização desta.

Quando analisada e atomizada, podemos perceber que a linguagem da qual depende a literatura é constituída de proposições elementares (em outras palavras, proposições indecomponíveis) e ela irá representar os fatos que existem no mundo, em nosso mundo - podemos destacar que a linguagem pode ser logicamente reduzida às suas proposições mais primárias, a partir das quais se derivam todas as outras proposições mais complexas. Segundo Moreno (2000), mostraram Frege e Russell que tais proposições podem assumir valor de verdade ou não, e que podemos considerar quaisquer proposições como elementares ao simbolizá-las por meio de letras do

\footnotetext{
${ }^{6}$ C. S. Peirce chega à mesma conclusão (para mais, consultar a obra The Essential Peirce, passagem 2:478).

${ }^{7}$ Ainda que S. Kripke, baseado em Wittgenstein, tenha uma posição contrária. Para tanto, é mister consultar o livro Wittgenstein on Rules and Private Language, publicado pelo filósofo norte-americano em 1982.

${ }^{8}$ Publicada postumamente em 1953.
} 
alfabeto (p, q, r, s) ${ }^{9}$. Wittgenstein demonstrou, por meio do aforismo 5.101 (TLP), que tais proposições, ao assumirem valor de verdade - aquilo que de fato interessa à filosofia, isto é, perseguir a verdade, supondo que tais proposições digam algo de concreto sobre o nosso mundo -, podem ser descritas em um esquema de não mais do que dezesseis alternativas lógicas. São estas:

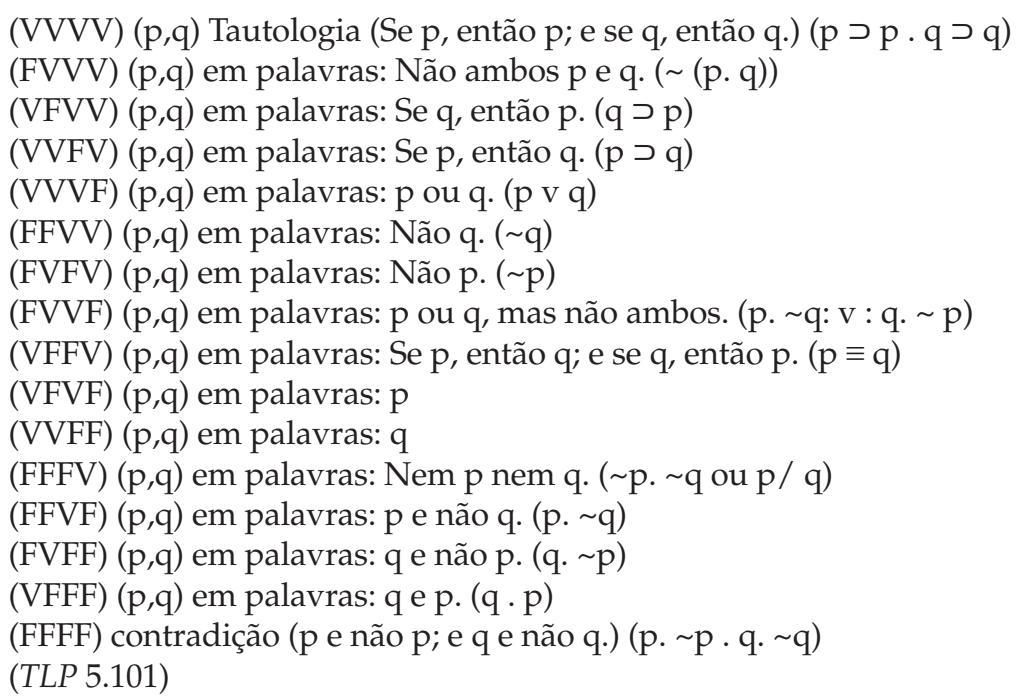

Mas então estaremos diante de um grande problema, pois que daí se infere que deve haver um elemento comum entre a proposição que diz e o fato que a representa (MORENO, 2000). Wittgenstein resolveu esse imbróglio ao postular que a linguagem é sempre isomórfica ao fato em suas articulações lógicas e biunívocas ${ }^{10}$. Segundo Moreno (2000, p. 16), em outras palavras, "podemos dizer que uma proposição é a imagem do fato". Ou seja, por meio de proposições somos capazes de criar representações mentais, ou então somos capazes de "traduzir" essas representações mentais por meio de proposições, pois que ambas as searas conservam regras lógicas semelhantes e necessárias. Ademais, cabe dizer também que o elemento linguístico e o não-linguístico carregariam consigo, portanto, características de similaridade (pois que, do contrário, a linguagem seria incapaz de representar o fato) e características sem similaridade (de outro modo seríamos incapazes de distinguir a representação do representado). A literatura "aproveita-se", amplamente, dessa brecha. Em linhas gerais, é assim que proposições e representações funcionam no interior da linguagem. Ora, uma vez conhecida a natureza das proposições, seus limites e virtudes, seguindo Wittgenstein novamente, pode-se dizer que, via de regra, somente teríamos acesso ao mundo por meio de fatos complexos - aglomerados de proposições indecomponíveis e articuladas logicamente. E é aqui que damos um passo no sentido a prioristico da linguagem e, por conseguinte, da literatura que se aproveita essencialmente desse elemento. Vejamos o que queremos dizer quanto a isto.

Assumindo o sentido wittgensteiniano da linguagem, esta passaria então a descrever estruturas logicamente possíveis, mas, como Moreno (2000, p. 21) busca esclarecer,

\footnotetext{
${ }^{9}$ Pensando em termos estritamente literários, podemos destacar algumas frases emblemáticas da literatura a fim de postular como tal sistema funcionaria. Pensemos em Shakespeare, por exemplo: "Ser ou não ser, eis a questão". Nesse sentido, teríamos:

- $\quad$ Ser $=p$; Não Ser $=\sim p$

- $\quad$ Eis a questão $=\mathrm{q}$

De modo que articulando as proposições elementares, na notação lógica teríamos:

- $\quad(p \vee \sim p) \leftrightarrow q$ (pensando que uma proposição implica, necessariamente, na outra)

- $\quad(\mathrm{p} \vee \sim \mathrm{p}) \rightarrow \mathrm{q}$ (pensando que apenas a primeira proposição implica na segunda, mas não o contrário)

- $\quad \mathrm{p} \vee \sim \mathrm{p} ; \mathrm{q}$ (pensando que as duas proposições são independentes entre si)

${ }^{10}$ Cf. aforismos $4.023 ; 4.04 ; 4.12$ e 4.26 do TLP.
} 
"nem todas se realizam efetivamente no mundo de nossa experiência". Por exemplo, a proposição "neva quando faz frio" apresenta, indica e elucida um fato que é típico ao nosso mundo. Por outro lado, se alguém sugere que "neva quando faz calor", não faz nada além de indicar um fato que, apesar de não ocorrer em nosso mundo, ainda assim, em algum lugar, possa vir a ocorrer, desde que, para tanto, não se tenha nenhuma impossibilidade lógica que obstrua seu caminho. Isso não seria o caso da proposição "neva e não neva simultaneamente no mesmo lugar", uma vez que tal sugestão indica um fato contraditório, um fato que não se pode dar nem aqui em nosso mundo, nem nas nossas imaginações, nem em qualquer outro lugar ou mundo possível. É exatamente isso que queremos dizer quando afirmamos na primeira parte desta exposição que nos é completamente impossível pensar ilogicamente, ou fora da lógica. Ao definir a noção de mundo como "estado de coisas", Wittgenstein se refere a todos e quaisquer mundos particulares em que ocorrem unicamente os fatos que são logicamente possíveis ${ }^{11}$. Quando fazemos literatura, estamos a criar exatamente esses mesmos mundos possíveis dentro de um estado da lógica natural - é este o a priori da literatura que escapou a Sartre. Curiosamente, todos os mundos a respeito dos quais podemos falar, narrar, escrever, tal como no caso da literatura, devem seguir esse mesmo esquema. As "literaturas" são, portanto, formas lógicas possíveis para as quais tentaremos, desesperadamente, fornecer ontologias que possam vir a preencher tais espaços - como se tentássemos encontrar o conteúdo com o qual preencher a forma, como se dispuséssemos a descrever a função para o molde que temos diante de nós. Problema é que tendemos a confundir a ontologia criada para esses mundos possíveis, que inventamos na literatura, com a ontologia que imaginamos buscar e esmiuçar em nosso próprio mundo. Buscamos o sentido que não serve ao nosso sentido, mas que pode imitá-lo ao simular a forma lógica de nosso próprio mundo. Quanto à literatura, devemos especular para esta a mesma ontologia que o Tractatus explicita:

É por essa razão que, no que concerne à ontologia (...), não devemos interpretá-la segundo os mesmos parâmetros da filosofia tradicional: não se trata de entidades irredutíveis e essenciais, de substâncias que são colocadas, mas de modelos, ou, como dissemos, de esquemas de seres, isto é, de formas puramente lógicas sem qualquer conteúdo-padrões de referência, como puros pontos geométricos sem dimensão, que não caracterizam seres, mas permitem caracterizar formas de seres. (MORENO, 2000, p. 21, grifo meu)

A literatura faz exatamente isso: caracteriza com acuidade formas de seres, pois que qualquer coisa ou qualquer elemento além disso extrapolaria a forma lógica do dizível. Quando "inventamos" personagens, enredos e histórias na literatura, apenas estamos a criar formas lógicas possíveis - tudo aquilo que poderia haver em outros mundos, mas não aquilo que temos em nosso. Inadvertidamente, poderíamos considerar então que a filosofia suscitada por uma obra literária caberia em nosso próprio universo, mas não atentamos ao fato de que qualquer filosofia resultante da obra literária será propícia àquela obra literária e não ao nosso mundo de fato. Foi isso que Sartre percebeu quando abandonou a empreitada literária com a qual tencionou "ampliar" o significado de sua obra filosófica, justamente ao notar que faltava ao mundo descrito a concretude filosófica que o nosso mundo exige ${ }^{12}$. A concretude de nosso mundo é consonante à filosofia, mas não é cabível ao mundo possível da literatura. Na medida em que buscamos conceitos cada vez mais universais, só poderemos fazê-lo por meio da filosofia, pois que esta irá conservar os limites lógicos daquilo que a ambas as esferas será possível dizer; quanto à literatura, esta

\footnotetext{
${ }^{11}$ Cf. Arley Moreno, 2000, pp. 19-23.

${ }^{12}$ Reflexão extraída pelo próprio Sartre inserida no documentário Sartre por ele mesmo (Direção: Alexandre Astuc/ Michel Contat, 197 min., 1976).
} 
funcionará para questionar tais conceitos, ou melhor ainda, para mostrá-los. Mas ao mostrá-los, por mais paradoxal que isto possa parecer, então já nos será impossível dizer qualquer coisa quanto a isso.

\section{A forma lógica do indizível}

Não é à toa que Wittgenstein abre o Tractatus dizendo que "o mundo é tudo que é o caso" (1 TLP) e, logo em seguida, que "o mundo é a totalidade dos fatos, não das coisas" (1.1 TLP). Ou seja, o nosso mundo primeiro é um estado de coisas e, ademais, são fatos complexos que descrevem o mundo. Mas se a linguagem é isomórfica ao mundo que temos, se pode descrevê-lo e torná-lo palatável a nós, é pelo motivo de que sua habilidade insere-se na possibilidade de logicamente descrevê-lo. Isto nos coloca no limite de nossa análise possível. A linguagem "exaure" o mundo ao descrevê-lo logicamente, ao descrever as formas possíveis; dos valores do mundo, porém, nada poderemos dizer. A linguagem descreve os fatos do mundo, descreve proposições articuladas, proposições indecomponíveis, e nada para além disso; a linguagem descreve a articulação possível. Os valores que pautam os fatos, porém, não podem ser expressos pela linguagem, mas podem ser mostrados. $\mathrm{O}$ valor se encontra além da descrição lógica do mundo. E pode haver no mundo alguma coisa além de fatos que não possamos expressar? Sim, são possíveis tais fatos, mas daí em diante nada poderemos dizer quanto a eles - são o místico, estão alheios à forma do logicamente "dizível"; melhor ainda, são o próprio indizível. Eis que chegamos à linha que demarca a fronteira da possibilidade da descrição lógica do que nos é cognoscível.

O primeiro filósofo a perceber e a se indagar acerca desse incômodo limite que a linguagem impõe ao homem na descrição daquilo que de fato seria importante - o indizível - foi o dinamarquês Sören Kierkegaard (JANIK \& TOULMIN, 1991). No decorrer de sua filosofia, Kierkegaard assume uma posição anti-intelectualista e se "revolta" contra a pura razão na tentativa de compreender questões estéticas e morais que, se tratadas de modo convencional, levariam o homem ao beco sem saída. Não é sem razão que também ele se volta à literatura - a obra Diário de um Sedutor ${ }^{13}$ enquadra-se perfeitamente nessa categorização. Percebera, portanto, que havia um claro limite a respeito daquilo que o homem poderia pensar e conjecturar. Mesmo ao tencionar buscar a verdade mais profunda, ficava este mesmo homem incapaz de comunicá-la aos demais, incapaz de expressar-se para justificar suas conjecturas. Resolveu este incômodo ao exigir do postulante à contemplação do "indizível" a filosofia do ato de fé, pois que somente esta ação nos permitiria acessar esse lado "indizível" tão necessário no decorrer da existência humana. "Desse modo Kierkegaard fez da separação da esfera dos fatos e da esfera dos valores uma separação absoluta", e, ademais, propôs a "separação da razão de qualquer coisa pertinente da esfera da vida" (JANIK \& TOULMIN, 1991, p. 181). O que Wittgenstein tentou demonstrar por meio de sua complicada filosofia foi exatamente isto, que o lado lógico do indizível, logo daquilo que nos seria o mais importante, está muito além da linguagem, é-nos, por fim, o limite da própria lógica. O lado lógico do indizível está além do que podemos mesmo postular, no entanto, é isto que nos importa no decorrer de toda a vida. Quem se propõe a fazer literatura, propõe-se a isso - a buscar o sentido mais profundo e recôndito que há nas coisas. A tentativa de extrair uma explicação racional, uma filosofia que há nas esferas da vida por meio da literatura, resultará, portanto, em um fracasso glorioso - os personagens nos demonstram o que é importante, mas filosoficamente, em linguagem, seremos incapazes de extrair

\footnotetext{
${ }^{13}$ Publicada em 1843.
} 
a filosofia que em tese haveria por detrás dos ensinamentos obtidos. A lógica do que nos é dizível demonstra que:

A implicação da teoria do modelo ${ }^{14}$ era que o "significado da vida" está fora da esfera do que podia ser dito; seria mais adequado referirmo-nos ao "significado da vida" como um enigma do que como um problema, porquanto não há maneira de o solucionar ou responder. Assim a teoria do modelo corrobora a noção de Kierkegaard de que o significado da vida não é um tópico que possa ser discutido por meio das categorias da razão. A verdade subjetiva só é comunicada indiretamente, através da fábula. (JANIK \& TOULMIN, 1991, p. 229)

Logo, o sentido só aparece na literatura por meio indireto (e isso porque se mostra), mas não pode aparecer na filosofia (e isso porque, curiosamente, não pode ser definível). Não pode haver sucesso na empreitada filosófica que se diga literária por conta disso, mas toda literatura que empregue elementos filosóficos não apenas nos será útil como também necessária - a escola de autores russos (Tolstói, Dostoievski, Tchékov, Gogol) é quiçá a mais bem-sucedida nesse sentido. Pode-se, todavia, indagar a respeito do que temos em mente quando dizemos que algo é "mostrável", mas não "definível". Ali há sempre o mujique russo que, em sua simplicidade, é capaz de ensinar ao aristocrata afetado o que de fato é importante na vida por meio de singelas ações: cuidar do próximo, arar a terra, contemplar a natureza, etc. Esse elemento também é fortemente notável na literatura francesa na qual, muito geralmente, o protagonista precisa superar-se a fim de romper com os artificialismos que o cercam. Tomemos o livro Em busca do tempo perdido de Proust como exemplo. $\mathrm{O}$ tempo todo o protagonista se debate com as suas impressões a respeito da vida e com os artificialismos exigidos pela "lógica" de sua sociedade. Podemos conjecturar o mesmo paradigma para a lógica, a linguagem e os valores da vida. A lógica prática, tal como demonstra Wittgenstein, exige que pensemos nos limites lógicos da "exaustão" linguística dos termos - como se cada palavra fosse um algoritmo a descrever as instâncias da vida. Fora do código, portanto, não há possibilidade lógica de sentido. Por outro lado, é impossível pensar que não haveria algo para além do código, aspecto este superior às formas que pautam a vida - para isso é necessário, portanto, romper com o "código". A forma lógica do indizível nos diz com isso que os nossos valores lógicos não servem para compreendê-la - aliás, se haveria mesmo uma lógica ao indizível é coisa que podemos questionar ainda que sempre infrutiferamente; é uma região inacessível ao sentido intelectual formal que nos permita criar padrões de análise. Mas é algo observável, que nos oferece vislumbres superiores de reflexão. Pensemos novamente na obra de Proust, sobretudo na relação do protagonista com a sua mãe. O protagonista, que aparece sempre descrito apenas como "eu"15, nutre por sua progenitora uma verdadeira relação de afeição, um amor incomparável, cuja força é insuperável mesmo se comparada às múltiplas outras demonstrações de afeição que este irá apresentar por outros personagens. No entanto, curiosamente, o "eu" descrito em primeira pessoa é completamente incapaz de pormenorizar e de explicar a força do amor que sente pela própria mãe: mostra-o, contudo, por meio de gestos. Quando dorme ao seu lado, quando a observa, quando se põe a pensar nela, sobretudo quando dela se recorda. De modo que este amor nos é apresentado por ações, por modos de vida e de conduta, jamais em palavras. As palavras, ordenadas logicamente, servem apenas para descrever o que se mostra - o amor. Palavras apenas dizem, mas não mostram. E essa será a única consideração que

\footnotetext{
${ }^{14} \mathrm{O}$ autor refere-se aqui ao Tractatus de Wittgenstein.

${ }^{15}$ Que no original traduz-se por je. O protagonista da obra (denominado Marcel), citado apenas duas vezes ao longo dos sete volumes, até hoje desperta inúmeras análises no que tange à sua identidade. Na maioria das vezes pensa-se que o protagonista seja o alter-ego do próprio Marcel Proust, mas as interpretações variam indo desde Proust, até a mera invenção de uma personagem que captura a atenção justamente por estar descrita apenas em primeira pessoa.
} 
poderemos realizar com relação a tudo que é indizível. É aqui que reside o talento do escritor: quanto mais vezes este nos fizer questionar acerca disso, mas importante será a sua obra. Essa característica também nos possibilita pensar que o escritor, ainda que a seu modo, também pode vir a ser um filósofo - filósofo não deste mundo, mas um filósofo para um mundo possível que, via literatura, é meramente ficcional.

\section{Sobre a (im)possibilidade de o escritor tornar-se um filósofo}

Ao escrever uma história, o escritor torna-se também o criador de um mundo logicamente possível - que, tal como vimos até aqui, e tal como explica Granger (1978), pode, inclusive, enganar-nos com relação à sua veracidade. Às vezes gostamos tanto de um livro, que nos esquecemos de que seus episódios são meramente possíveis em um mundo qualquer, mas não em nosso. Assim, a fim de dar lastro ao seu mundo possível, o escritor, subitamente, começa a preenchê-lo com ontologias fabricadas, simulacros que em muito se parecem às ontologias que temos em nosso mundo. Afinal, é necessário criar um fundo de verdade mesmo ao que é, por essência, fictício. E por que fazemos isto? Por que evocamos uma ontologia? Estamos tão condicionados ao substrato lógico de nossa realidade, a preencher as formas lógicas, que esta dimensão nos será uma condição para a criação de qualquer coisa que possamos inventar - é aí que as coisas se embaralham e começamos a tomar o meramente possível como aquilo que se passa de fato em nosso mundo. Confundimos os mundos possíveis com o nosso mundo (GRANGER, 1978). Ora, mas se o escritor cria um mundo possível, a filosofia deste novo mundo não necessariamente precisa ser a mesma que a nossa - os personagens não estão condicionados à filosofia deste mundo. $\mathrm{O}$ escritor, caso queira (e tiver talento para tanto), pode, por consequência, ser também "um filósofo ficcional" - aliás, mais do que isto. O filósofo não cria nada, ele intui verdades que mais tarde serão ordenadas em categorias formais. O escritor, porém, pode ir além: pode inventar filosofias, pois que em seu mundo a filosofia pode ser nova, pode ser outra coisa que a nossa - precisa respeitar apenas o substrato lógico que subjaz em sua possibilidade de criação como vimos até aqui: trata-se de uma filosofia essencialmente ficcional, semelhante à nossa, mas não a mesma. É assim que o escritor pode ser também, à sua maneira, um filósofo em sentido figurado, ou, melhor ainda, um criador de novas filosofias. Ao ler sobre essa nova perspectiva filosófica, o leitor começa a se questionar também se o que se dá no mundo possível é passível de consideração em nosso mundo. Isso nos desperta (e também confunde) para inúmeras outras instâncias. Vejamos o que queremos dizer com isto ao destacarmos, novamente, a obra de Proust.

Tal como ressalta Kristeva (1996) é difícil saber exatamente a respeito do que se trata a obra de Proust. Estamos diante de uma pletora de tópicos importantes e que nos fazem refletir sobre a natureza de diversas temáticas - amor, arte e, sobretudo, o tempo. Mais abaixo, indo-se além da epiderme do romance, temos ainda a questão da linguagem, das sensações e de como as metáforas podem nos remeter ao mundo e ao sentido que fazemos dele. Proust vai introduzindo diversas novas considerações que nos despertam para inúmeras outras possibilidades e tudo isto a partir do seu protagonista. Resolve a partir das sensações, o abismo que separa a comunicação do indizível. Marcel Proust:

Pode apenas conceber uma obra literária como uma "obra de sentimento" focando "naquilo que ainda não está pronto para vir à tona". Tal texto faria frente ao abismo entre a linguagem e experiência vivida (...). Isso abre caminho para a impressão, que é o que se redime da fraqueza dos signos linguísticos. Palavras são úteis apenas quando exercem um "poder 
evocativo" sobre a nossa "sensibilidade" e demonstram, assim, uma afinidade com um tipo de "música latente". (KRISTEVA, 1996, p. 252) ${ }^{16}$

Curioso notarmos que aqui, em Proust, o escritor também tem como missão romper esse abismo intransponível entre linguagem lógica e valores. Em seu universo, o autor francês resolve isto por meio das impressões. Insere nas personagens uma característica receptiva à impressão associativa que imprime e dá significado às coisas. A sensibilidade está no limite. O protagonista da história termina por desenvolver uma linguagem própria, aquilo que Kristeva (1996) concebeu como a sensação tornando-se uma linguagem. Como se no decorrer da história inteira, os indivíduos partilhassem esse fundo comum: a sensação repartida como denominador comum. Assim, as personagens não se comunicam unicamente em um nível linguístico, mas também na sensação que evocam uns aos outros. Ora, isto, transposto ao nosso mundo, transforma-se em uma concepção de difícil implementação (não custa relembrar que ficção e realidade não são a mesma coisa) - decerto que por vezes sabemos o que sentem aqueles que de nós estão mais próximos, se tristeza ou alegria, raiva ou satisfação, e assim por diante. Mas aplicar isto como um todo a um esquema funcional intelectual plausível, é coisa difícil de conceber. No entanto, essa mera sugestão já nos abriria a porta para uma série de novas considerações filosóficas e psicológicas. Isso nos faz atentar que talvez a necessidade de se superar a própria estrutura lógica da linguagem seja também necessária em qualquer mundo lógico possível que possamos conceber. Outra coisa que também não podemos esquecer-nos acerca de Proust é da sua habilidade em "saborear" o tempo, em desnudá-lo em vívidas partes ao suscitar blocos inteiros de lembranças. Em Proust, as memórias não acodem ao espírito simplesmente por meio da inteligência que nos perpassa; devem, mais do que tudo, estar associadas a sensações recônditas, que do ponto de vista intelectual, jamais seríamos capazes de recuperar. Ao comer uma única madeleine ${ }^{17}$, um bloco inteiro de memórias advém-lhe ao espírito, como se aquele pedaço do doce lhe fosse a parte mais cara na reconstituição de um imenso quebra-cabeças:

A impressão é associativa e situacionista. Ela obscurece os limites entre o que é sentido e o que é pensado, entre pessoas e os locais nos quais elas são encontradas, entre espaço e tempo. Ao privá-las de suas identidades, isso as erradica. Ao mesmo tempo, ao restitui-las ao tempo e lugar incomensuráveis, devolve-lhes suas vidas, ressuscitando-os nessas "ressurreições da memória" que transcrevem uma "nova verdade" às sensações dos tempos idos. (KRISTEVA, 1996, p. 256, grifo da autora $)^{18}$

Kristeva (1996) adiciona que a vida inteira Proust ressentiu-se de ser chamado de "psicologista", sempre refutou que tais associações técnicas e estilísticas estivessem presas ao seu nome, mas como ele mesmo nos diz, percebia a sua obra como uma sorte de terapia. "Proust insistia que seu trabalho possuía poderes terapêuticos, ou até de ressurreição: as ideias vêm a nós como as sucessoras das lamentações" (KRISTEVA, 1996, p. 262) ${ }^{19}$. Curiosamente, essa mesma ideia de terapia por meio da linguagem

\footnotetext{
${ }^{16}$ No original: "Can only conceive of a literary work as a 'work of feeling' focusing on 'what is not yet ready to come forth'. Such a text would rise up against the abyss between language and lived experience (...). This paves the way for impression, which is what makes up for the weakness of linguistic signs. Words are useful only when they exert an 'evocative power' over our 'sensibility', and display a kinship with a sort of 'latent music'"

${ }^{17}$ Um tipo de doce francês.

${ }^{18}$ No original: “The impression is associative and situationist. It blurs the boundaries between what is felt and what is thought, between people and the places in which they are found, and between space and time. By depriving them of their identity, it eradicates them. At the same time, by restoring them to time and places beyond measure, it returns their lives to them, resuscitating them in those 'resurrections of memory' that transcribe a 'new truth' onto the sensations of time past".

${ }^{19}$ Em inglês: "Proust insisted that his work had therapeutic, if not ressurective powers: ideas come to us as the successors of griefs".
} 
nos remete diretamente ao que Wittgenstein fez com relação à análise das proposições lógicas. Em suma, temos tanto a literatura como a filosofia a funcionarem como modo de vida, tentando ancorar sua função em esclarecer os tormentos e as confusões com as quais lidamos cotidianamente. É assim que Proust inventa sua própria "filosofia ficcional", típica ao universo de lembranças perdidas e tempos distantes. Superar a lógica da linguagem por meio das sensações e impressões é uma forma de mostrar o indizível ao ir muito além do que aqueles que percorrem o caminho de Guermantes podem supor de início.

\section{Considerações finais}

De tudo quanto se foi dito até aqui, continua uma brecha em nosso foco de análise - tema este que talvez seja propício para excursões futuras nos campos da literatura, linguagem e lógica: seria a literatura a manifestação de um mundo solipsista? Cunhado com base unicamente na vontade do escritor? Ora, mas se isto é assim, como podemos nos identificar com as veredas abertas por cada autor? Tais perguntas nos mostram apenas que deve haver um campo comum aos indivíduos mesmo na maior solidão de espírito - que não pode ser outra coisa do que a lógica inserida na linguagem. Esta lógica, no entanto, só faz algum sentido se podemos preencher, à nossa maneira, a estrutura que esta nos oferece. Enchemo-la com o "ser", ou ao menos com aquilo que desejamos que "seja". Pretendemos encontrar no mundo a base de nossas suposições, que nos são dadas de antemão com a lógica, e assim procuramos por aquilo que possa lhe corresponder. Escapa, contudo, ao sentido lógico da coisa, a esfera dos valores - que não somos capazes de definir com precisão, mas que, por outro lado, somos capazes de contemplar em fugazes vislumbres que temos no cotidiano: ao testemunhar o amor de uma mãe por um filho, a descoberta da felicidade, a tristeza da perda, etc. Tudo isso não cabe na lógica atomizada da linguagem, pois que esta exaure a descrição lógica do mundo. Ficamos então diante do indizível, que podemos indicar meramente com a linguagem. Dizê-lo, no entanto, é impossível. Então fazemos tudo isto por meio daquilo que encontramos no caminho, daí a função da arte, e em nosso caso específico, da literatura. É na leitura que descobrimos mundos possíveis, repletos de analogias que se devem aos seus autores diferentes, novas filosofias que esperamos descobrir no nosso próprio mundo. Ao retornarmos, entretanto, vemo-nos diante de um mundo parecido com aquele, mas no qual as peças não se encaixam, pois que não foram cunhadas com a exata precisão necessária. Resta-nos, assim, traçar uma tênue distinção entre o que lemos e o que temos. Foi por isto que empreitadas filosóficas literárias (que tencionavam se remeter ao concreto) não deram certo, na medida em que suas contrapartes, literaturas filosóficas (ainda que ficcionais), prosperaram. Importante, portanto, saber buscar com clareza (indo de Wittgenstein a Proust, cada um a seu modo que no-la propuseram primeiro) a terapia para as ideias; saber que formas logicamente possíveis são completadas com ontologias particulares e que lhe sejam peculiares. Isto pode esclarecer o pensamento e evitar que tenhamos por resultado a incompatibilidade da filosofia enquanto literatura, tal como ocorreu a Sartre.

Correspondência: Rodrigo César Lima. Pontifícia Universidade Católica de São Paulo - PUC-SP. Rua Monte Alegre, 984. Perdizes. São Paulo - SP - Brasil. CEP: 05014-901. E-mail: rodrigo_ccl@hotmail.com.

Apoio financeiro: Nenhum.

Conflito de interesses: Nenhum.

Todos os autores leram e aprovam a versão final submetida à revista Em curso. 


\section{Bibliografia}

GRANGER, G. G. Observações acerca do uso da língua em filosofia. In: NATTIEZ, J.J. (Org.). Problemas e métodos de semiologia. São Paulo: Martins Fontes. 1978.

JANIK, A.; TOULMIN, S. A Viena de Wittgenstein. Trad. de Álvaro Cabral. Rio de Janeiro: Campus. 1991. KRISTEVA, J. Time and Sense: Proust and the experience of Literature. Translated by Ross Guberman. New York: Columbia University Press. 1996.

LEOPOLDO E SILVA, F. Ética e literatura: ensaios introdutórios. São Paulo: Editora Unesp. 2004.

MORENO, A. R. Wittgenstein: os labirintos da linguagem. São Paulo: Moderna; Campinas: Editora da Universidade de Campinas. 2000.

SARTRE, J. P. Que é a literatura?. Trad. de Carlos Felipe Moisés. 3ª ed. São Paulo: Editora Ática. 2004.

WITTGENSTEIN, L. Tractatus Logico-Philosophicus. Trad., notas e ensaio introdutório de Luiz Henrique L. Santos. $2^{\text {a }}$ ed. São Paulo: Edusp. 1994.

Recebido em: 29/Mai/2018 - Aceito em: 25/Set/2018. 